\title{
GRANITOS ORNAMENTALES DE LA REGIÓN MARIATEGUI
}

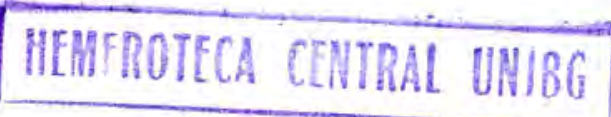

R E S U M E N

Wilmer Arenas Oporto ${ }^{1}$

El estudio comprende la identificación de las características ornamentales de los granitos que afloran en la Región José Carlos Mariategui. La metodología utilizada para la evaluación de estas rocas está de acuerdo a las normas internacionales y se divide en fases; comprende desde la recopilación de la información hasta la apertura de la cantera de extracción.

El afloramiento estudiado pertenece a la zona de la cordillera de la costa y se ubica en la Pampa del Palo, muy cerca al puerto de Ilo.

\section{A B S TRACT}

The study recognises the identification of the ornamental characteristics of the granites that appear in the José Carlos Mariategui Region. The methodology used for the evaluation of these rocks is according to the international norms and is divided in phases, from the gathery of the information until the opening of the extraction quarry.

The studied fluorishing belongs to the area of the coordillera on the coast and is located in the "Pampa del Palo", very close to the port of Ilo.

\section{INTRODUCCIÓN}

Los granitos ornamentales son rocas naturales, de procedencia plutónica con textura media a gruesa y una composición mineralógica variada y principalmente de un aspecto vistoso o atractivo a la vista. Se consideran granitos ornamentales a los granitos, granodioritas, pegmatitas, tonalitas, dioritas y gneises.

El afloramiento estudiado se encuentra ubicado en la Pampa del Palo, a 10 kilometros del puerto de Ilo (Lámina № 01).

La accesibilidad a la zona de estudio es por la carretera asfaltada costanera Tacna - Ilo. Su cercanía al puerto de llo y su fácil accesibilidad hacen de este depósito muy interesante para una probable explotación y comercialización al mercado exterior.
Los objetivos del estudio fueron:

- Determinar si los granitos que afloran en la zona Sur del Perú poseen características ornamentales, como para ser comercializados en el mercado de la construcción nacional e internacional.

- Conocer el potencial de las rocas graníticas ornamentales de la región Sur del Perú.

- Determinar el grado de fracturamiento de los macisos rocosos de la región, para poder extraer bloques comerciales de granitos.

- Determinar la ubicación geográfica de los afloramientos de granitos ornamentales.

Ingeniero Geólogo, especializado en Mineralogía y Cristalografía. 
Lámina 1. Mapa de Ubicación.

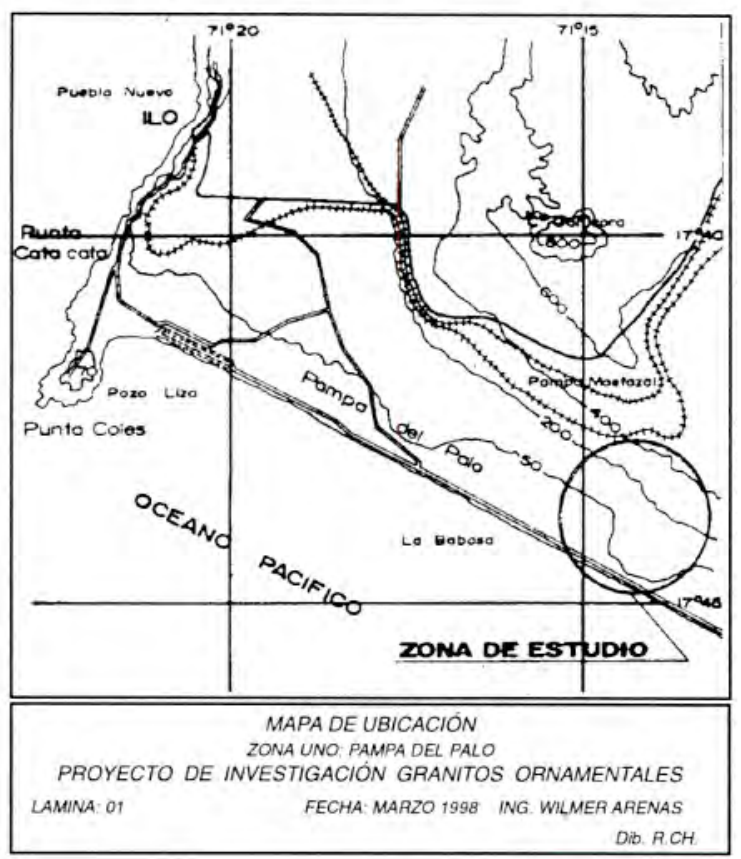

Lámina 2. Mapa Geológico.

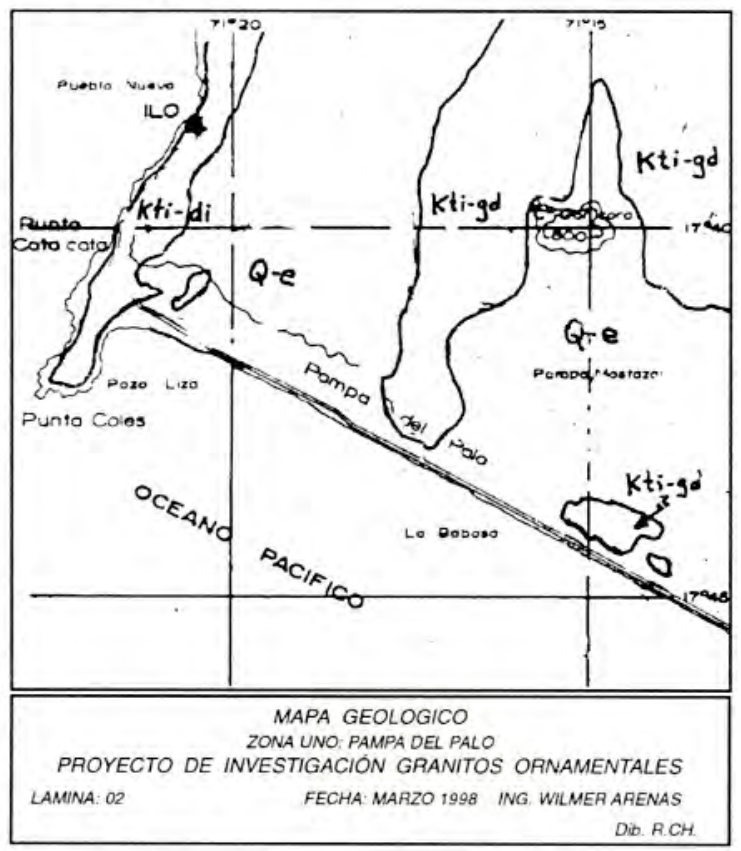

No se conocen de estudios realizados referentes a la evaluación de rocas ornamentales en la región. La utilización de este material se ha dado en muchas edificaciones en el Perú desde los Incas, con sus grandes obras arquitectónicas realizadas en piedra de gran tamaño. En Tacna este material ha sido muy utilizado en la construcción, como en la Catedral, el Paseo Cívico y otras obras.

\section{DESCRIPCIÓN DE LA METODOLOGÍA DE INVESTIGACIÓN}

Para realizar la investigación se ha conseguido la metodología que se utiliza para evaluar los yacimientos, de rocas ornamentales en la Unión Europea, especificamente en España, considerando que este país es el primer productor mundial de estas rocas. La metodología se divide en las siguientes fases:

Fase 1: Recopilación de Información. Consiste en la recopilación de información geológica, topográfica, minera, contenida en estudios locales, tesis, boletines geológicos, publicaciones internacionales especializadas, etc. Además fue recomendable consultar a organismos y asociaciones profesionales, productores y empresas comercializadoras para conocer la problemática concreta de cada roca. La escala de esta información fue a 1/50,00, 1/100,000. Esta recopilación permitió realizar una primera selección de las zonas de interés real o potencial.

Fase 2: Exploración de Campo. El afloramiento de la pampa del palo es estudiada con mayor detalle e importancia en los parámetros siguientes:

\section{Propiedades Generales del Afloramiento.}

a) Morfología. Las caracteristicas geométricas del maciso rocoso consisten en un afloramiento de forma irregular, con un área de 6 kilometros aproximadamente y una profundidad de 8 a 10 kilometros. Presenta una zonación horizontal con la presencia de oxidaciones en la parte Norte, mientras que en la parte Sur la roca se presenta fresca. (Foto 1).

b) Fracturación. El diaclazamiento se presenta en cuatro familias, un espaciamiento variado de $0.5 \mathrm{a}$ 3.0 metros. El espaciamiento ha dado lugar a la formación de grandes bolones (Foto 2).

c) Características de la Roca. El afloramiento presenta las siguientes características mineralógicas:

Composición mineralógica : Variada

Tamaño del grano

: Medio a grande

Color
: Gris Claro 
Textura

Homogeneidad

: Granuda

Oxidaciones

Otras alteraciones
: Facies suaves

: Superficiales

: Meteorización media.

\section{Factores Condicionantes de la Explotabilidad.}

La zona de estudio presenta los siguientes factores:

a) Tamaño del Yacimiento. La extensión del yacimiento es importante, el afloramiento es de $6 \mathrm{~km}^{2}$ aproximadamente y de acuerdo a los indicios geológicos, su profundidad puede alcanzar 8 a 10 kilómetros. Se le puede considerar como de tamaño irregular.

b) Recubrimientos. Gran parte del macizo rocoso se encuentra cubierto por material suelto producto de la meteorización y la deposición eólica, su potencia no es importante en la parte central mientras que en las zonas laterales puede alcanzar hasta 4 metros.

c) Topografía y Accesos. El relieve de la zona es suave y su accesibilidad es buena, se realiza por la carretera asfaltada llo - Tacna (carretera costanera). El depósito granítico se ubica a un costado de esta carretera y a 20 kilómetros del puerto de llo.

d) Impacto ambiental. La explotación de esta cantera no causaría mayor alteración visual como tampoco en la vida animal y vegetal en la zona, no existen. La contaminación acústica y atmosférica debe ser controlada y en cuanto al impacto fisiográfico este debe ser tomado en cuenta al momento del diseño de la explotación.

e) Existencia de Canteras Próximas. En los alrededores del afloramiento no existen canteras de este mismo material pero si existe una de conchuela (coquina).

f) Infraestructura Industrial. Este aspecto es, considerado como muy importante, ya que esta ubicado a solo 20 kilómetros del puerto industrial y zona franca de llo. Esto debido a la infraestructura energética y el poco transporte que demandaría su explotación.

Todos estos datos se recogen en una ficha de indicios (Tabla 1), que sintetiza los datos de la zona.

Tabla 1. Ficha de Indicios.

Tipo de Roca
Localización
Hoja de Carta Nacional №
Nombre del paraje
№ de muestras
Punto toma de muestra
Fotografías
Láminas delgadas
Topografia
Datos particulares

GRANODIORITA

\section{Afloramiento}

$\begin{array}{lll}\text { Formación Geológica } & \text { : Coord de la Costa } \\ \text { Extensión } & : & 2,0 \times 3,0 \mathrm{~km} . \\ \text { Recubrimiento } & : \text { Variado } \\ \text { Diaclasado } & : \text { Voderado } \\ \text { Estructura y morfología } & : \text { Oxidos de Hierro } \\ \text { Alteraciones } & : \text { N } 2 \times 3 \text { metros } \\ \text { Tamaño de Bloques } & : \text { Ninguna } \\ \text { Otras características } & : \text { Bueno } \\ \text { Accesos } & : \text { No existe } \\ \text { Vegetación } & : \text { Si existe } \\ \text { Cambios de facies } & : \text { Ninguna } \\ \text { Canteras Proximas } & : \text { Si } \\ \text { Presencia de Bolos } & : \text { Ninguna } \\ \text { Punto toma de bloques } & \end{array}$

\section{Roca}

Denominación
Color
Tamaño de grano
Composición
Discontinuidades
Orientaciones
Otras caracteristicas

Granodiorita

Gris claro

Medio a grueso

Acida

Ninguna

Ninguna

Ninguna

\section{Observaciones}

Fecha

Marzo de 1998

Fase 3: Características Geológicas del Yacimiento. Las propiedades estudiadas son la calidad del afloramiento, la homogeneidad, oxidaciónes y la fracturación. En conjunto definen la calidad del yacimiento y la viabilidad de su explotación.

Cada una de estas propiedades depende de una serie de parámetros, como se indica en la tabla 1, que muestra los índices de valoración de estas propiedades, los cuales serán utilizados en etapas más avanzadas de la investigación. Todos estos parámetros se obtienen por medición u observación directa. 
En primer lugar se considera la vistosidad de la roca o calidad ornamental que se obtiene en muestras de briquetas pulidas. Este criterio se basa en los gustos, modas y tendencias coyunturales del mercado, por lo que es sumamente variable, y por ello no debe ser eliminatorio.

\section{CALIDAD DEL AFLORAMIENTO.}

Hace referencia a la homogeneidad, la fracturación y recubrimiemto del mismo.

a) La Homogeneidad. Se trata de estudiar los cambios litológicos, variaciones de color y tamaño de grano, presencia y distribución de megacristales, producidos por diferenciación magmática, etc. Mediante la medición de las foliaciones magmáticas y tectónicas se buscan las estructuras del granito que marcan las direcciones de corte de los bloques a extraer, denominados hilos o ley de la piedra por los canteros. Estas direcciones preferentes se ponen de manifiesto por la orientación de la mica y los megacristales.

b) La Fracturación. Es uno de los factores de mayor peso en la explotabilidad del yacimiento, ya que de la densidad y tipo de diaclasado va a depender la posibilidad de extraer bloques comerciales.

En primer lugar es preciso conocer la distribución espacial del sistema de fracturamiento, con el fín de detectar las direcciones de debilidad preferentes. Las familias de fracturas observadas en el campo se pueden visualizar mediante diagramas en rosa. El estudio de la fracturación debe centrarse en la identificación de la geometría y espaciados de las familias de diaclasas que existen. Para ello es conveniente utilizar la proyección estereográfica, muy apropiada para el manejo y tratamiento de datos angulares.

Los espaciados entre diaclasas de una misma familia constituyen el factor principal condicionante del tamaño del bloque a extraer. Para estudiar este parámetro se representa mediante histogramas de frecuencias en el que se representan la suma de los espaciados correspondientes a ciertos intervalos predefinidos.

La tabla 2 nos proporciona los intervalos seleccionados para rocas graníticas; han sido definidos a partir de los tamaños comerciales mínimos extraidos en las canteras para bloques de calidad estándar.
Tabla 2. Tipos de espaciados de diaclasas según intervalos.

\begin{tabular}{|c|c|}
\hline INTERVALO(m) & ESPACIADO \\
\hline $0-1$ & REDUCIDO \\
\hline $1-2,5$ & MODERADO \\
\hline $2,5-6,25$ & AMPLIO \\
\hline $6,25>15,62$ & MUY AMPLIO \\
\hline$>15,62$ & $\begin{array}{c}\text { EXTREMADAMENTE } \\
\text { AMPLIO }\end{array}$ \\
\hline
\end{tabular}

Lámina 3. Diagrama en rosa de las familias de fraturas detectadas en un ärea.

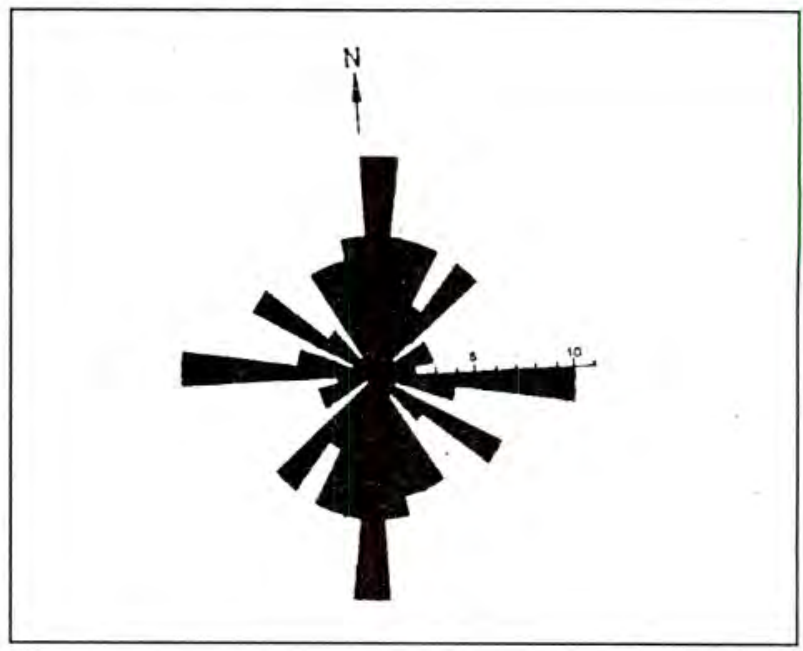

Tabla 3. Tipos de diaclasas según su continuidad.

\begin{tabular}{|c|c|c|}
\hline \multirow{2}{*}{$\begin{array}{c}\text { DENOMINACIÓN } \\
\text { DIACLASA }\end{array}$} & \multicolumn{2}{|c|}{ C ON T IN U I D A D } \\
\cline { 2 - 3 } & TI P O & L O N G I T U D \\
\hline Menor & $\begin{array}{c}\text { Muy Baja } \\
\text { Baja }\end{array}$ & $\begin{array}{c}<1 \mathrm{~m} \\
1-3\end{array}$ \\
\hline Mayor & Media Alta & $\begin{array}{c}3-10 \mathrm{~m} \\
10-20 \mathrm{~m}\end{array}$ \\
\hline Principal & Muy Alta & $>20 \mathrm{~m}$ \\
\hline
\end{tabular}

Fuente: Muñoz, P. et al. (1989).

Fase 4: Investigación de Laboratorio. Esta investigación consiste en el estudio de muestras de la roca en secciones delgadas, bajo microscopio . 
Este estudio se ha realizado en los laboratorios de microscopia del INGEMMET en Lima.

\section{CALIDAD DE LA ROCA.}

Este estudio considera dos propiedades importantes:

a) Alterabilidad actual y potencial.

b) Calidad Mecánica de la Roca.

La alterabilidad se analizó en tres muestras de secciones delgadas, una ubicada en la zona Norte del depósito (muestra 1, foto 3). La muestra 2 ubicada en la zona Central del depósito (foto 4 ) y la muestra 3 , en la parte Sur del yacimiento (foto 5).

a) Alteración o deterioro actual. De acuerdo al estudio petrográfico en el microscopio se concluye que el zoneamiento en el yacimiento está definido de norte a sur. En el norte la alteración o deterioro, según la tabla 5 es alta, con indices 3 a 4 (foto 3). En la parte media del afloramiento la alteración es baja con índices de 1 a 2 (foto 4). La mejor zona de acuerdo con la alteración es la zona Sur, que presenta índices de 0 a 1 considerada como muy baja (foto 5 ).

La alteración o deterioro potencial se observa en el microscopio y de acuerdo a la composición mineralógica observada se puede indicar que este granito presenta un índice potencial de 2,5 considerado como medio.

Generalmente se aceptan que los elementos más móviles en el transcurso de la meteorización de los granitos son Calcio (Ca), Sodio ( $\mathrm{Na}$ ), Magnesio (Mg) y Potasio (K). El Hierro ( $\mathrm{Fe}$ ) tiene una movilidad muy variable, transformándose con-frecuencia de $\mathrm{Fe}+{ }^{2} \mathrm{a}$ $\mathrm{Fe}+{ }^{3}$.

La valoración de la alterabilidad se efectúa con la tabla 4:

Tabla 4. Valoración de la alterabilidad.

\begin{tabular}{|c|c|}
\hline INDICE DE ALTERACIÓN & VALORACIÓN \\
\hline $0-1$ & Muy baja \\
\hline $1-2$ & Baja \\
\hline $2-3$ & Media \\
\hline $3-4$ & Alta \\
\hline
\end{tabular}

b) La Calidad Mecánica de la Roca. Para conocer este parámetro se realizan diversos ensayos normalizados, siguientes:

- Tamaño de grano

- Absorción y peso específico

- Resistencia al desgaste por rozamiento

- Ensayos de heladicidad

- Resistencia a la compresión

- Resistencia a la flexión

- Resistencia al impacto

Cuando a los resultados de estas pruebas se les unen los obtenidos en los ensayos realizados previamente para determinar la calidad, como estudio petrográfico, rayos $\mathrm{x}$, análisis químico y pulido, se tiene bien caracterizada la roca y pueden deducirse sus usos preferentes de acuerdo con los valores obtenidos. El uso recomendado puede ser interior o exterior, de enchape o pișo.

\section{CONCLUSIONES Y RECOMENDACIONES}

- En la Región José Carlos Mariategui se encuentran afloramientos de rocas graníticas con caracteristicas ornamentales en dos zonas, en la coordillera de la costa y la cadena occidental de los Andes del sur del Perú.

- La ubicación geográfica de los afloramientos de granitos es el factor determinante para su caterabilidad, debido a los bajos costos de transporte y accesibilidad a la red de energía eléctrica.

- El afloramiento de la Pampa del Palo - Ilo, pertenece a la zona de la cordillera de la Costa, presenta las características ornamentales y de yacimiento requeridas para ser explotado.

- Existen otras zonas con afloramientos de rocas graníticas ornamentales con las características como para ser comercializadas en el mercado internacional.

- La explotación de estas rocas y otras de características ornamentales debería incentivarse por ser una fuente de generación de empleo porque las características que presentan estas rocas son muy buenas. 
Tabla 5. Calidad de la Roca - Parámetros que comprende.

\begin{tabular}{|c|c|c|c|c|}
\hline \multicolumn{2}{|c|}{ INDICES } & \multirow{2}{*}{$\begin{array}{l}\text { PROPIE- } \\
\text { DAD }\end{array}$} & \multirow{2}{*}{ PARAMETROS } & \multirow{2}{*}{$\begin{array}{l}\text { OBTEN- } \\
\text { CIÓN DE } \\
\text { PARÁ- } \\
\text { METROS }\end{array}$} \\
\hline $1^{\circ} \mathrm{O}$ rden & $2^{\circ} \mathrm{Orden}$ & & & \\
\hline \multirow{5}{*}{$\begin{array}{c}\text { Calidad } \\
\text { de la } \\
\text { roca }\end{array}$} & \multirow{4}{*}{$\begin{array}{l}\text { Altera- } \\
\text { bilidad }\end{array}$} & $\begin{array}{c}\text { Deterioro } \\
\text { Actual }\end{array}$ & $\begin{array}{l}\text { - Microfacturación } \\
\text { transgranular } \\
\text { - Microfacturación } \\
\text { intragranular } \\
\text { - Min. alt. sup y } \\
\text { retrodiagénesis }\end{array}$ & $\begin{array}{l}\text { Análisis } \\
\text { petrográfico } \\
\text { Análisis } \\
\text { petrográfico } \\
\text { Análisis } \\
\text { petrográfico }\end{array}$ \\
\hline & & $\begin{array}{l}\text { Deterioro } \\
\text { Potencial }\end{array}$ & $\begin{array}{l}\text { - Tamaño de grano } \\
\text { - Borde de grano } \\
\text { - Heterogeneidad } \\
\text { textual } \\
\text { - Recristalización } \\
\text { - Zonación de } \\
\text { plagioclasas } \\
\text { - Estructura Fk } \\
\text { - Microfractur. } \\
\text { transgranular } \\
\text { - Microfractur. } \\
\text { intragranular } \\
\text { - Composición } \\
\text { mineralógica }\end{array}$ & $\begin{array}{l}\text { Análisis } \\
\text { petrográfico } \\
\text { Análisis } \\
\text { petrográfico } \\
\text { Análisis } \\
\text { petrográfico } \\
\text { Análisis } \\
\text { petrográfico } \\
\text { Análisis } \\
\text { petrográfico } \\
\text { Análisis } \\
\text { petrográfico } \\
\text { Análisis } \\
\text { petrográfico } \\
\text { Análisis } \\
\text { petrográfico } \\
\text { Análisis } \\
\text { petrográfico }\end{array}$ \\
\hline & & $\begin{array}{l}\text { Meteori- } \\
\text { zación } \\
\text { Potencial }\end{array}$ & $\begin{array}{l}-\% \mathrm{Mg} \\
-\% \mathrm{Na} \\
-\% \mathrm{~K} \\
-\% \mathrm{Ca}\end{array}$ & $\begin{array}{l}\text { Análisis } \\
\text { quimico } \\
\text { Análisis } \\
\text { químico } \\
\text { Análisis } \\
\text { quimico } \\
\text { Análisis } \\
\text { quimico }\end{array}$ \\
\hline & & $\begin{array}{l}\text { Oxida- } \\
\text { ción }\end{array}$ & $\begin{array}{l}\text { - Grado de } \\
\text { alteración en } \\
\text { atmósferas } \\
\text { contaminantes } \\
\text { - Grado de } \\
\text { alteración }\end{array}$ & $\begin{array}{l}\text { Ensayo de } \\
\text { atmósferas } \\
\text { contami- } \\
\text { nantes } \\
\text { Ensayo de } \\
\text { alteración }\end{array}$ \\
\hline & \multicolumn{2}{|c|}{ Calidad Mecánica } & $\begin{array}{l}\text { - Absorción de } \\
\text { agua } \\
\text { - Peso específico } \\
\text { aparente } \\
\text { - Módulo de } \\
\text { haladicidad } \\
\text { - Coeficiente } \\
\text { resistencia } \\
\text { compresión } \\
\text { - Coeficiente } \\
\text { resistencia flexión } \\
\text { - Coeficiente } \\
\text { resistencia } \\
\text { desgaste por } \\
\text { rozamiento } \\
\text { - Coeficiente } \\
\text { dilatación lineal } \\
\text { térmica }\end{array}$ & $\begin{array}{l}\text { Ensayo de } \\
\text { absorción } \\
\text { Ensayo de } \\
\text { P.E.A. } \\
\text { Ensayo de } \\
\text { heladicidad } \\
\text { Ensayo de } \\
\text { compren- } \\
\text { sión } \\
\text { Ensayo de } \\
\text { flexión } \\
\text { Ensayo } \\
\text { desgaste } \\
\text { por roza- } \\
\text { miento } \\
\text { Ensayo } \\
\text { dilatación } \\
\text { lineal } \\
\text { térmica }\end{array}$ \\
\hline
\end{tabular}

Tabla 6. Determinación del deterioro mineralógico OrdazEsbert.

\begin{tabular}{|c|c|c|c|}
\hline GRADOS & $\begin{array}{l}\text { NIVELES DE } \\
\text { DETERIORO } \\
\text { DE FELDES- } \\
\text { PATOS }\end{array}$ & $\begin{array}{l}\text { NIVELES DE } \\
\text { DETERIORO } \\
\text { DE MAFICOS }\end{array}$ & $\begin{array}{l}\text { NIVELES DE } \\
\text { DETERIORO } \\
\text { DE CUARZO }\end{array}$ \\
\hline 0 & $\begin{array}{l}\text { No alterado, } \\
\text { aparentemente } \\
\text { sano. }\end{array}$ & $\begin{array}{l}\text { No alterado, } \\
\text { sano. }\end{array}$ & $\begin{array}{l}\text { Aparentemente } \\
\text { sano. }\end{array}$ \\
\hline 1 & $\begin{array}{l}\text { Con } \\
\text { microfisuras } \\
\text { aisladas de } \\
\text { orden inferior al } \\
\text { del tamaño de } \\
\text { grano. Ligera } \\
\text { alteración } \\
\text { secundaria. }\end{array}$ & $\begin{array}{l}\text { Alterado sólo } \\
\text { marginalmen- } \\
\text { te y/o en las } \\
\text { lineas de } \\
\text { exfoliación. }\end{array}$ & $\begin{array}{l}\text { Con } \\
\text { microfisuras de } \\
\text { orden inferior al } \\
\text { tamaño de } \\
\text { grano. }\end{array}$ \\
\hline 2 & $\begin{array}{l}\text { Con } \\
\text { microfisuras } \\
\text { aisladas de } \\
\text { orden del } \\
\text { tamaño de } \\
\text { grano, } \\
\text { interconexiones } \\
\text { entre } \\
\text { microfisuras. } \\
\text { Alteraciones } \\
\text { inferiores al } \\
50 \% \text { de la } \\
\text { superficie del } \\
\text { grano. }\end{array}$ & \begin{tabular}{|l|} 
Alteración \\
marginal, con \\
pequeñas \\
manchas de \\
alteración \\
repartidas por el \\
interior del \\
grano \\
Microfisuras.
\end{tabular} & $\begin{array}{l}\text { Con } \\
\text { microfisuras de } \\
\text { orden de } \\
\text { tamaño de } \\
\text { grano. } \\
\text { Interconexio- } \\
\text { nes entre las } \\
\text { microfisuras. }\end{array}$ \\
\hline 3 & $\begin{array}{l}\text { Microfisuras } \\
\text { abundantes } \\
\text { Areas de } \\
\text { alteración } \\
\text { superior al } 50 \% \\
\text { de la superficie } \\
\text { del grano. }\end{array}$ & $\begin{array}{l}\text { Areas de } \\
\text { alteración } \\
\text { inferiores al } \\
50 \% \text { de la } \\
\text { superficie del } \\
\text { gano. } \\
\text { Microfisuras. }\end{array}$ & $\begin{array}{l}\text { Microfisuras } \\
\text { abundante y } \\
\text { principios de } \\
\text { subindividuali- } \\
\text { zación granular }\end{array}$ \\
\hline 4 & $\begin{array}{l}\text { Microfisuración } \\
\text { abundante. } \\
\text { Areas de } \\
\text { alteración } \\
\text { ocupando } \\
\text { prácticamente } \\
\text { todo el grano. }\end{array}$ & \begin{tabular}{|l|} 
Areas de \\
alteración \\
superior al $50 \%$ \\
de la superficie \\
del grano. \\
Microfisura- \\
ción abundante.
\end{tabular} & $\begin{array}{l}\text { Microfisuración } \\
\text { abundante } \\
\text { subindividuali- } \\
\text { zación granular }\end{array}$ \\
\hline
\end{tabular}

Fuente: Muñoz, P. et al 1989. 


\section{REFERENCIASBIBLIOGRÁFICAS}

LLOPIS. L. (1992). "La Piedra Natural y su normalización". Madrid - España.

OBIS. J Y CARRASCO. J (1988). "La normalización y certificación como instrumentos de apoyo tecnológico al sector de las rocas ornamentales".

\section{HEMEROTECA CENTRAL UNIBG}

AENOR (1988). "Gestión y Aseguramiento de la calidad" Madrid.

(1989) "Normalización y Certificación". Madrid. LOEMCO (1995). "Manual de rocas ornamentales".

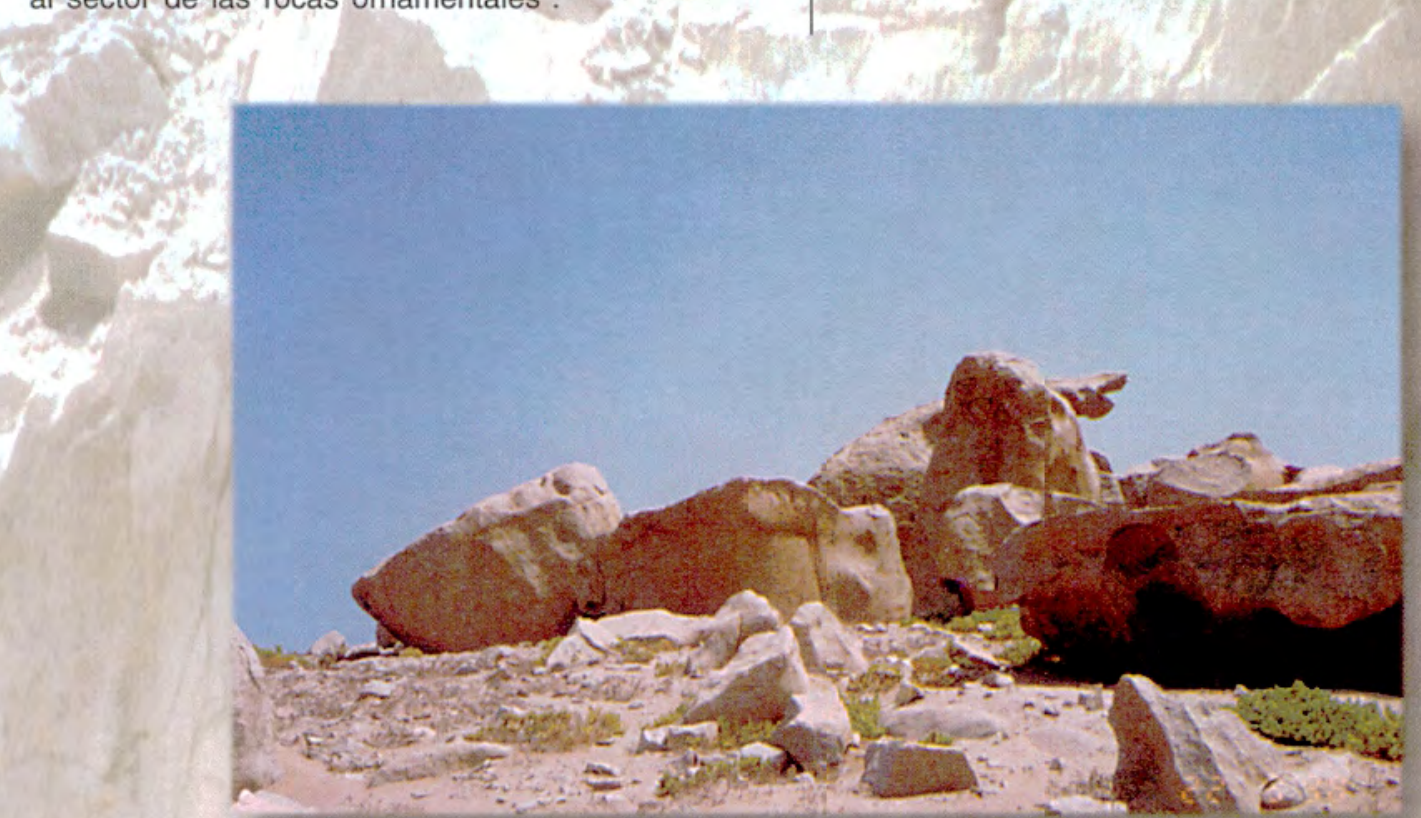

Foto 1. En la superficie se observa bloques de grandes dimensiones, redondeados por la meteorización.

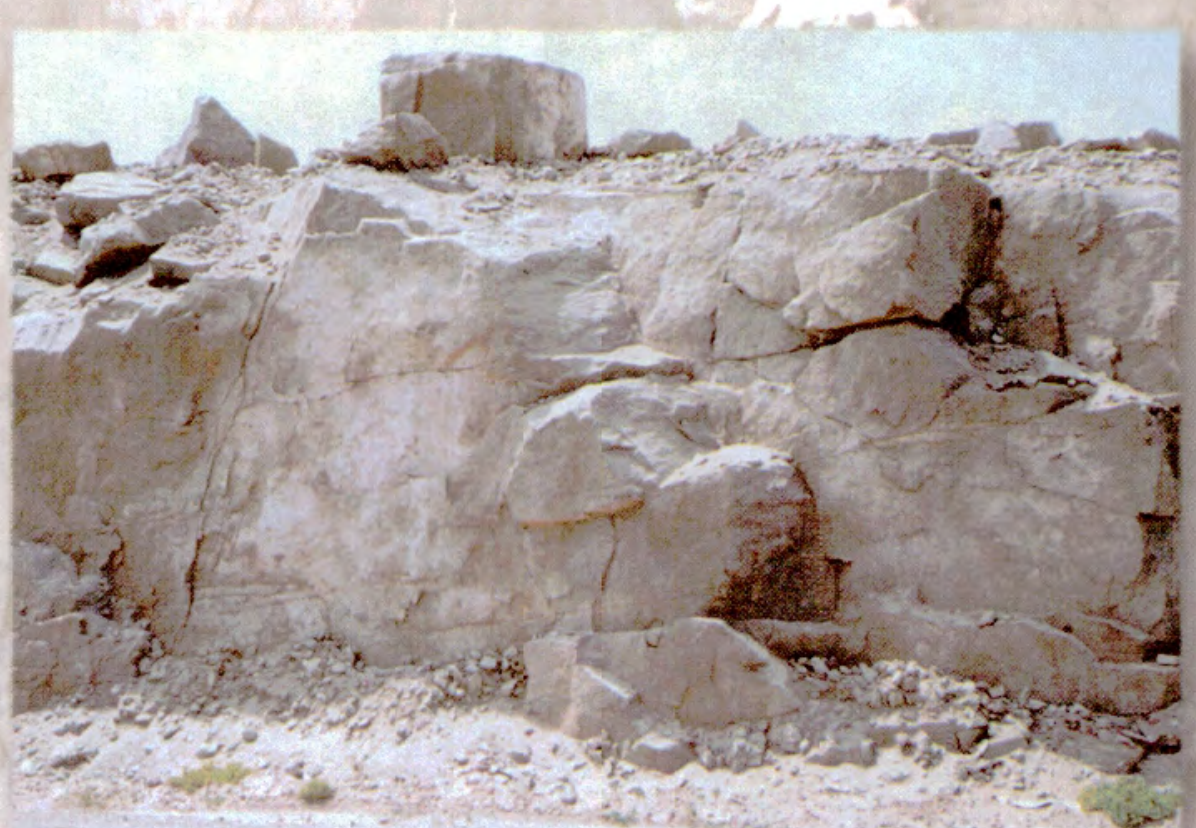

Foto 2. Se observa el fracturamiento del depósito con buen espaciamiento entre diaclasas.

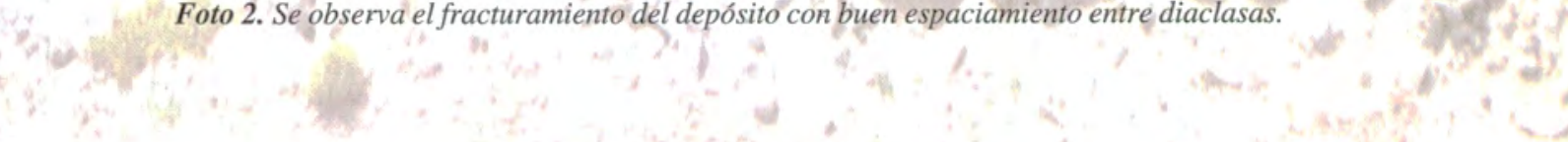




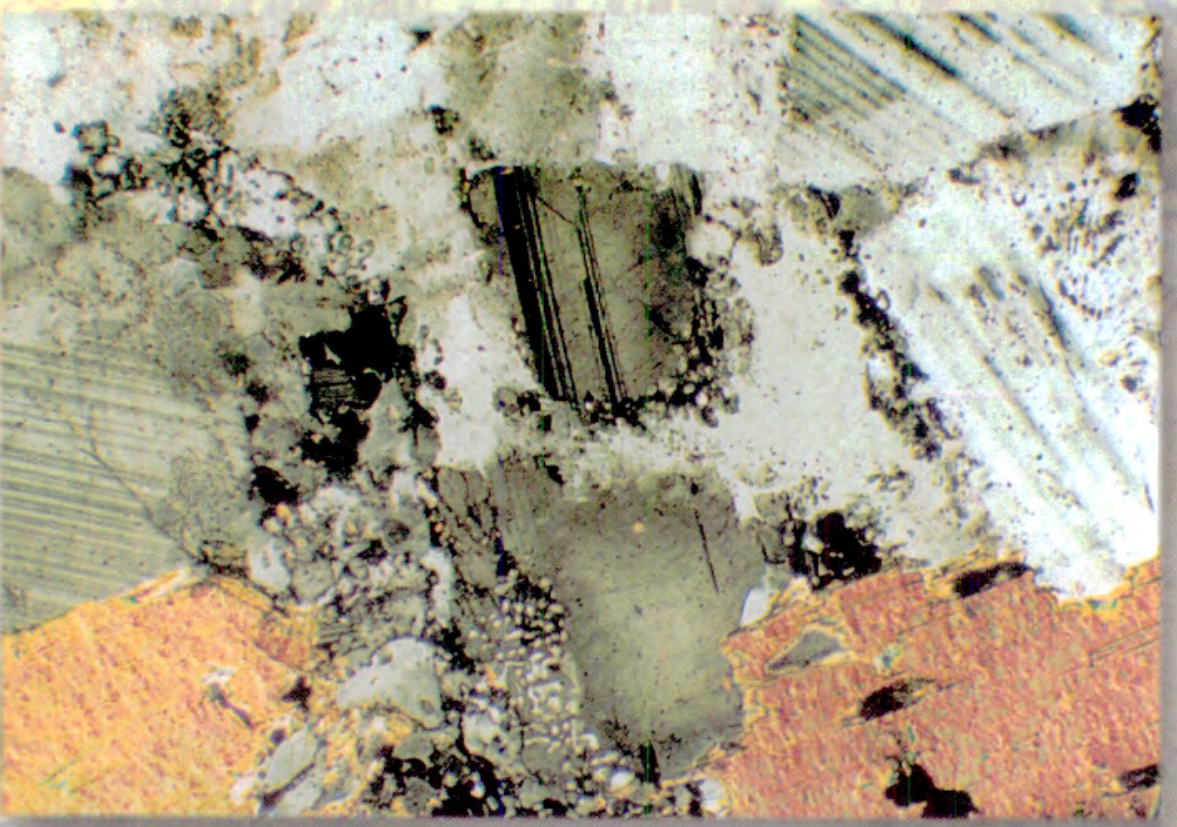

Foto 3. Muestra 01: Mineralogia: cuarzo, plagioclasa alterada, abundante biotita y hematita.

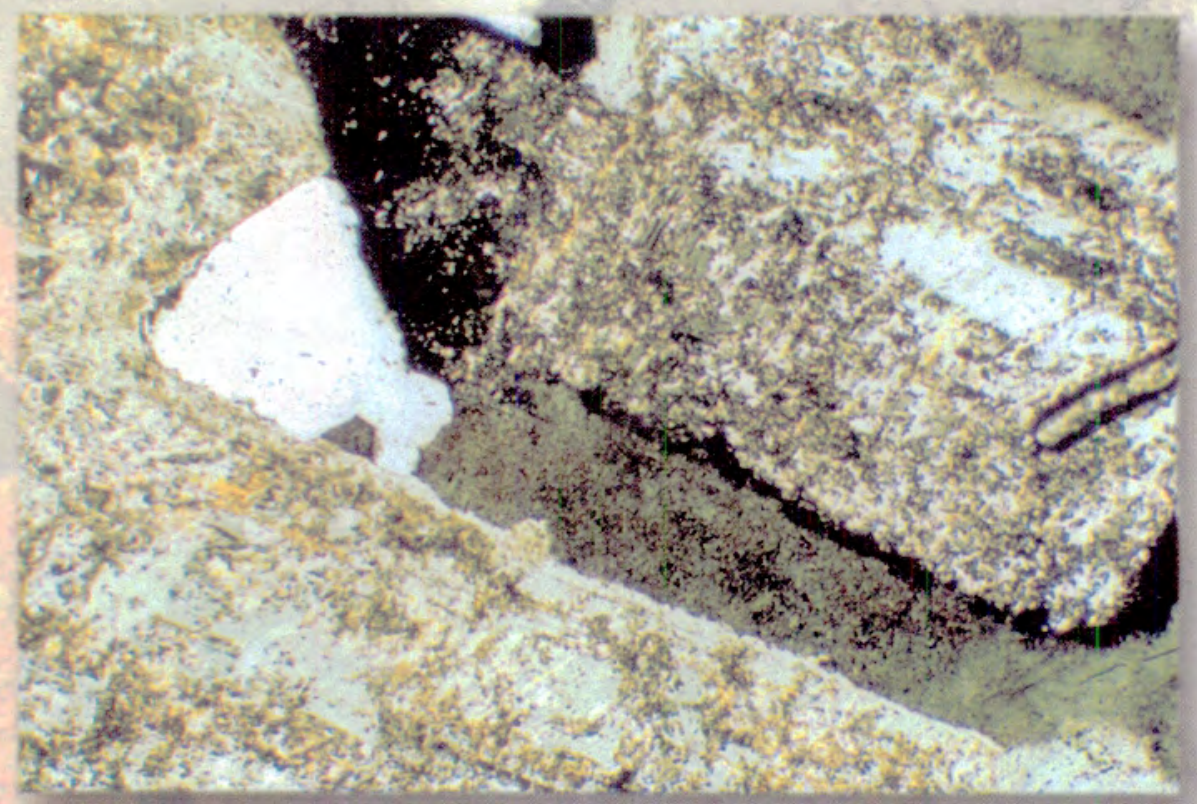

Foto 4. Muestra 02: Mineralogia: Plagioclasa en fenocristales alterados a sericita, pequeñas inclusiones de cuarzo intersticial. 


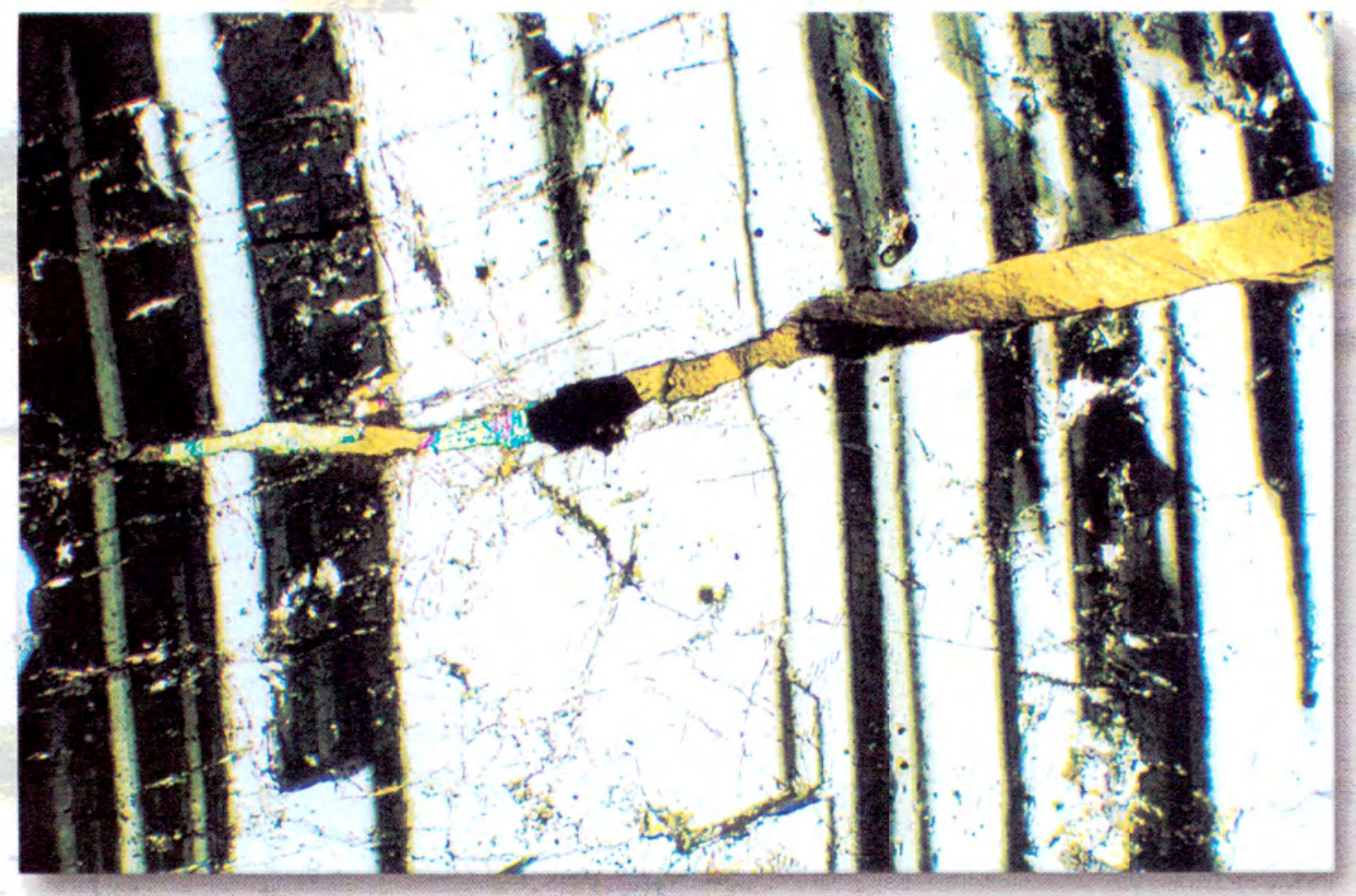

Foto 5. Muestra 03: Mineralogia: cristales de plagioclas fresca inclusiones de clorita y epidota.

HEMEROTECA CENTRAL UNBBG 